oportunidades serão limitadas em razão de condições objetivas. Nas suas palavras, "elementos que se combinam para que um trabalhador se dê bem profissionalmente não se restringem, porém, para os entrevistados, àqueles de algum modo pertencentes ao indivíduo, tais como escolaridade e características pessoais. Alguns desses elementos são intrínsecos ao trabaIho propriamente dito e à empresa contratante, bem como à qualidade do trabalho executado" (p. I I I).

Para a autora, isso significa que a percepção desses sujeitos aproxima-se da noção de qualificação como construção/relação social.

Sendo assim, sua pesquisa contraria o discurso da culpabilização individual, pelo qual os indivíduos se auto-responsabilizariam pelo seu destino pessoal, obscurecendo os condicionantes sociais objetivos. Se Kober aponta diversas pesquisas que mostram que os sujeitos têm atribuído o desemprego à falta de qualificação dos trabalha- dores - o que, na maioria das vezes, significa falta de credenciais escolares e/ou qualidades pessoais -, seus entrevistados parecem ter uma visão diferente a respeito do fenômeno, já que compreendem que o processo de qualificação "não depende apenas da escola e nem apenas do trabalhador" (p. I 44), mas também do seu reconhecimento por parte da empresa e das condições de trabalho que ela oferece. Essa diferença entre seu pressuposto e a realidade encontrada poderia ter sido mais bem explicitada, pois valorizaria os resultados da pesquisa. De toda forma, trata-se de um texto estimulante, cuja leitura é recomendada àqueles que se interessam pelas relações entre educação e trabalho.

Gisela Lobo B.P.Tartuce

Departamento de Pesquisas Educacionais da Fundação Carlos Chagas gtartuce@fcc.org.br

\section{PLURALIDADE CULTURAL E INCLUSÃO NA FORMAÇÃO DE PROFESSORAS E PROFESSORES: GÊNERO, SEXUALIDADE, RAÇA, EDUCAÇÃO ESPECIAL, EDUCAÇÃO INDÍGENA, EDUCAÇÃO DE JOVENS E ADULTOS}

\author{
Margareth Diniz e Renata Nunes \\ Vasconcelos (orgs.)
}

Belo Horizonte: Formato, 2004, I87p.

(Série Educador em Formação)

Os estudos sobre currículo têm indicado a necessidade premente de se repensar a formação dos professores no sentido de possibilitar-lhes maior contato com os subsídios que movimentam o debate curricular atual. Entende-se que os professores não apenas aplicam, mas reinterpretam as diretrizes curriculares que lhes são apresentadas a partir de suas próprias leituras de mundo e que, por isso, precisam refletir coletivamente sobre sua prática, de forma a desenvolverem consistentemente tanto o ensino como a si mesmos como profissionais.

Quando o que se busca é a oferta de uma escola que respeite as diferenças, a preocupação com a prática docente se acentua, pois o preconceito e a segregação ocorrem, no mais das vezes, de maneira sutil no cotidiano escolar. Lidar com as diferenças "exige sensibilidade diante de qualquer discriminação no trato cotidiano, evitando que os próprios docentes sejam a fonte de juízos, atitu- 
des e preconceitos que desvalorizem a experiência de certos grupos sociais, culturais, étnicos ou religiosos" !.

É nessa problemática que percebo inserida a coletânea aqui comentada, não como uma mera reunião de textos afins, mas como um conjunto coeso de reflexões que, na perspectiva de um multiculturalismo crítico, abordam separadamente as diferenças, usando linguagem cuidadosa e acessível. Com isso demonstra-se a preocupação de oferecer aos professores importantes ferramentas teórico-conceituais para lidarem, de forma mais consistente, com a pluralidade cultural no cotidiano escolar.

A questão do gênero é tratada no texto "O que produz o silenciamento das mulheres no magistério?", de Margareth Diniz, Renata Vasconcellos e Shirley Miranda. As autoras fazem um resgate histórico da relação entre o gênero feminino e a educação, problematizando os discursos sociais produzidos nesse contexto.

Mostram de que forma, ao longo da história, a inserção da mulher no magistério ocorreu sem que fosse rompida a vinculação do seu papel doméstico e de mãe. Esse processo colaborou com a naturalização dos papéis sociais da mulher e, conseqüentemente, para o seu silenciamento. Consideram, porém, que com o desenvolvimento do conceito de gênero foi possível um estudo mais aprofundado da questão, uma vez que ele possibilita a reflexão sobre o espaço feminino numa perspectiva histórica e global.

Apontam diversas situações que revelam as representações dos papéis relativos aos gêneros no espaço escolar, como no "discurso da queixa" e no discurso "amoroso". A partir da análise desses dois discursos perguntam: até que ponto a "escolha" pelo magistério não seria uma forma de

I SACRISTÁN, J. G. Currículo e diversidade cultural. In: SILVA, T. T.; MOREIRA, A. F. (orgs.) Territórios contestados. o currículo e os novos mapas político culturais. Petrópolis: Vozes, 1995. p.82-113. adequação, por parte das mulheres, a um papel social já determinado? A expressão "escolha" é largamente discutida sob a perspectiva da psicanálise. Nesse sentido, são questionados os discursos já construídos a respeito da presença feminina no magistério, buscando-se tensionar criticamente sua escolha profissional com vistas à maior flexibilidade quanto às opções.

Em "À flor da pele", Paulo Henrique de Queiroz Nogueira constrói uma argumentação enriquecida com analogias que apresentam a sexualidade como algo múltiplo e diverso.

Em sua argumentação, mostra que não há o "sentido" correto para a sexualidade. No entanto, ao ser construída socialmente, ela vai sendo caricaturada de forma a discriminar algumas das formas de manifestá-la. Ainda que façamos parte da construção desses sentidos há momentos em que situações nos constrangem, pois ferem essas certezas estabelecidas. Valendo-se da psicanálise, o autor busca respostas para uma série de interrogações sobre a relação entre a "fantasia" e essas situações consideradas constrangedoras. Afirma que, ao discutir o conceito de fantasia, Freud desenvolve um quadro teórico que "desculpabiliza a sexualidade ao retirá-la do campo da moralidade e do pré-julgamento; ao mesmo tempo, leva a pensar que as fantasias dos infelizes estão nas formas como a subjetividade se expressa e dá sentido à existência" (p.62).

Para o autor a escola, levando em conta esse quadro teórico, busca satisfazer um novo discurso sobre a sexualidade no qual ela não esteja enquadrada em padrões morais. Questiona, porém, a forma como o novo discurso sobre a sexualidade se constrói, sobretudo nos parâmetros curriculares nacionais, no texto "Pluralidade cultural/orientação sexual" que, apesar de não restringir a sexualidade a uma moralidade religiosa, pode direcionar seu enquadramento a uma outra moralidade: a científica.

No lugar de um ensino prescritivo sugere mais atenção aos sujeitos e aos sentidos que estes 
atribuem a sua sexualidade. É a partir da compreensão desses sentidos que se pode elaborar formas de intervenção mais adequadas e tolerantes às diferenças.

A questão racial é discutida por Nilma Lino Gomes em "Práticas pedagógicas e questão racial: o tratamento é igual para todos/as?". A autora inicia demonstrando como a retomada de lembranças de ocorrências racistas pode subsidiar reflexões que colaborem com a formação docente. Aponta porém algumas dificuldades para promover tais reflexões, sobretudo devido aos processos de naturalização do racismo desenvolvidos na sociedade.

Na escola essa naturalização também ocorre e estorva o desenvolvimento de uma pedagogia da diversidade, uma vez que faz com que os professores não se sintam indignados o suficiente para promoverem uma ação efetiva contra o racismo. Segundo a autora, uma forma de aguçar a indignação é oferecer dados que revelem a realidade do racismo. Buscando oferecer um pouco desses instrumentais, a própria autora passa a apresentar algumas inquietantes estatísticas a respeito da inserção educacional do negro no Brasil.

Indica também a necessidade da superação do mito do "paraíso racial" atribuído ao país, vez que ele nega o conflito. Melhor seria, exemplifica, trabalhar a história do Brasil de forma a desvendar um passado que possa contribuir com o desenvolvimento da identidade negra brasileira, indicando que isso poderia ser feito pela abordagem das questões da diáspora dos negros e do papel exercido pela religiosidade na rearticulação da identidade negra no Brasil.

Argumenta que a tarefa pedagógica de desenvolver o debate que tenha como eixo a luta contra o racismo deve ser coletiva, pois se trata de algo que envolve valores universais, como a democracia, a tolerância e a convivência com a diversidade.

O texto "Da educação especial à educação inclusiva", de Margareth Diniz e Mônica Rahme, oferece um panorama histórico dos discursos produzidos sobre as pessoas com "deficiência" e suas implicações no tipo de atendimento escolar. Mostra que tradicionalmente a abordagem da deficiência era feita com caráter assistencialista. Aponta o surgimento da educação especial, ou seja, um modelo educacional especialmente concebido para os deficientes, situado à margem do sistema regular de ensino e orientado pelo discurso médico. Com a Assembléia Geral da Organização das Nações Unidas - ONU -, em 198I, cunha-se a concepção do deficiente como pessoa com direitos. Assim, o discurso jurídico passa a indicar (juntamente com o médico) o que fazer com os deficientes.

Diniz e Rahme discutem as implicações da perspectiva do déficitna educação de maneira geral e na educação especial. Defendem a mudança dessa perspectiva, que parte do que a pessoa não tem, para a perspectiva da produção, "na qual o educador e a educadora teriam de buscar conhecer melhor a originalidade e a dinâmica do sistema de aprendizagem de seus alunos, para ajudálos a encontrar o caminho das possíveis conquistas" (p. | 21$)$.

A partir daí, analisam dois modelos que orientam as atuais formas de atendimento escolar às pessoas com deficiência: o da integração e o da inclusão. $\bigcirc$ da integração, prevê a especialização do atendimento ao portador de deficiência até o momento em que ele se mostre pronto para o ingresso na escola comum. Já o modelo da inclusão propõe que seja ofertada uma mesma escola para todos, de forma que as dificuldades e as diferenças não sejam um impedimento para a sociabilidade, mas um indicador dos rumos dos projetos pedagógicos a serem desenvolvidos.

Concluem destacando que um dos empecilhos à inclusão é o fato de vivermos numa "sociedade do estereótipo". Consideram que todos possuem estereótipos; o problema ocorre quando, a partir deles, discrimina-se e exclui-se aqueles que não se encaixam nos padrões escolhidos. 
Outra questão colocada pela criação de estereótipos ocorre em relação aos povos indígenas. $\bigcirc$ texto de Macaé Maria Evaristo e Patrícia Moulin Mendonça - "Índios de verdade? A diversidade cultural, a questão indígena e a escola" expressa uma preocupação com os problemas gerados pelo estabelecimento de um "modelo indígena".

O que seriam "índios de verdade"? Numa tentativa de desconstruir a forma tradicional de perceber os indígenas, as autoras denunciam que a expressão "índios" é freqüentemente utilizada de modo genérico e no passado. Assim se forma uma imagem segundo a qual os indígenas são todos iguais e sua cultura não se transforma ao longo do tempo. Contra isso, sobre as diferenças existentes entre os vários povos indígenas e sobre sua historicidade, ou seja, eles não são estáticos culturalmente, transformam costumes, tecnologias, economia e crenças ao longo do tempo.

Exemplificando essa historicidade, assinalam os vários períodos e orientações da relação entre os povos indígenas e o Estado brasileiro: o Serviço de Proteção ao Índio - SPI (criado em I 910), a Funai ( 1967), o Estatuto do Índio promulgado em 1973, as organizações não governamentais ONGs - das décadas de 1970, até as garantias anunciadas pela Constituição de 1988, que "reconheceu a pluralidade cultural e o multilingüismo, a organização social, os costumes as crenças e línguas das sociedades indígenas que convivem com a sociedade brasileira" (p. |47).

Coerentes com a concepção de que cada povo indígena mantém suas especificidades, as autoras passam a tratar designadamente dos índios xacriabás. Resgatam sua história destacando o processo de demarcação das terras e a relação com o espaço escolar da rede oficial do Estado de Minas Gerais e do município de Itacarambi. Relatam as expectativas e decepções que as lideranças xacriabás mantinham em relação ao atendimento escolar. Ao observarem a escolarização dos xacriabás, as autoras destacam uma série de práti- cas que constituem interessantes pontos de reflexão para a educação de maneira geral. A autonomia na organização do trabalho escolar, caracterizada por uma gestão comunitária, possibilita, por exemplo, que a própria comunidade escolha os professores. Essa autonomia estende-se para a escolha e confecção do material didático, permitindo que cada vez mais os próprios professores elaborem-nos. Como conseqüência, o saber local pode fazer-se presente no currículo, colaborando para o fortalecimento da identidade desse povo.

Em "A educação de jovens e adultos: a diversidade de sujeitos, práticas de exclusão e inclusão das identidades em sala de aula", Charles Moreira Cunha e Maria Clemência de Fátima Silva, apresentam as iniciativas de educação de jovens e adultos ao longo da história e fazem uma reflexão sobre as particularidades que marcam esse público.

Mostram que mesmo considerando todas as iniciativas, o Estado tem deixado lacunas, sobretudo em relação ao financiamento dessa modalidade de ensino. Diante de tais deficiências tomam a frente da Educação de Jovens e Adultos EJA - outros atores sociais como "sindicatos, centrais sindicais, ONGs, igreja e associações de bairro. Em muitos casos, essas organizações transferem suas experiências para os sistemas públicos de ensino, sejam eles na cidade ou no campo" (p. 165).

A respeito dos professores, relatam que era comum encontrar argumentos que justificavam a escolha pela EJA, devido ao trabalho ser considerado mais fácil do que aquele com crianças e adolescentes. Evidenciam, porém, que essas concepções têm mudado e que os espaços ocupados pelo tema nos vários setores da sociedade movimentam um intenso debate sobre essa modalidade de ensino.

As questões levantadas sobre a EJA indicam a necessidade de o projeto pedagógico levar em conta as singularidades dos/as alunos/as, sobretudo, no que se refere a raça, gênero e geração. As 
autoras lamentam, porém, a forma fragmentada pela qual tais questões têm sido abordadas nas escolas. Lembram que no caso dos/as professores/as, o papel que exercem como profissionais e acadêmicos/ as tem sobreposto outros aspectos de sua identidade. Admitem a dificuldade de se promover um trabalho que valorize os sujeitos diante de identidades sobrepostas. Nesse sentido, indicam que "a escola poderá criar situações em que todos, professores/as e alunos/as venham perceber o próprio cotidiano, conflitos, contradições e ambigüidades. Deixar falar não somente a voz, mas o corpo, o gênero, a raça e a geração" (p. |80- |8|).

Numa última consideração a respeito da obra como um todo, é possível dizer que, mesmo diante de diferenças diversas, muitos dos caminhos propostos pelas autoras assemelham-se. É recorrente em seus textos a indicação da reflexão individual e coletiva da comunidade escolar a respeito do relacionamento com o diferente. Eles também evidenciam a necessidade da exploração/ estudo do tema, no que, aliás, esta obra se adianta, ao oferecer várias dimensões da relação entre educação e pluralidade cultural. No entanto, o ponto em que os textos mais convergem é o da defesa da inclusão, que implica dar atenção à voz dos diferentes mediante a viabilização de sua presença no espaço escolar, respeitando as suas particularidades. Somente com essa presença é possível a cada um o conhecimento de si mesmo e do outro, e de si mesmo no outro, fortalecendo as bases de um coletivo de pessoas diferentes, mas iguais.

Alexandre Cândido de Oliveira Campos

Professor de Ensino Fundamental e

Mestrando da Faculdade de Educação da USP acandido@usp.br 